\title{
QUEEN'S
UNIVERSITY
BELFAST
}

\section{Online communication, social media and adolescent wellbeing: A systematic narrative review}

\author{
Best, P., Manktelow, R., \& Taylor, B. (2014). Online communication, social media and adolescent wellbeing: A \\ systematic narrative review. Children and Youth Services Review, 41, 27-36. \\ https://doi.org/10.1016/j.childyouth.2014.03.001
}

\section{Published in:}

Children and Youth Services Review

\section{Document Version:}

Peer reviewed version

Queen's University Belfast - Research Portal:

Link to publication record in Queen's University Belfast Research Portal

\section{Publisher rights}

(c) 2014 Elsevier Ltd. This manuscript version is made available under the CC-BY-NC-ND 4.0 license http://creativecommons.org/licenses/by$\mathrm{nc}-\mathrm{nd} / 4.0 /$ which permits distribution and reproduction for non-commercial purposes, provided the author and source are cited.

\section{General rights}

Copyright for the publications made accessible via the Queen's University Belfast Research Portal is retained by the author(s) and / or other copyright owners and it is a condition of accessing these publications that users recognise and abide by the legal requirements associated with these rights.

Take down policy

The Research Portal is Queen's institutional repository that provides access to Queen's research output. Every effort has been made to ensure that content in the Research Portal does not infringe any person's rights, or applicable UK laws. If you discover content in the Research Portal that you believe breaches copyright or violates any law, please contact openaccess@qub.ac.uk. 


\title{
Online Communication, Social Media and Adolescent Wellbeing: A Systematic Narrative Review
}

\begin{abstract}
Background: Much debate and polarisation exists regarding the impact of online social technologies on the mental wellbeing of young people.

Objective: To systematically review and synthesise current empirical research on this topic, identifying both the beneficial and harmful effects of online communication and social media technology amongst young people.
\end{abstract}

Methods: A systematic narrative review of research published between January 2003 and April 2013, retrieved using rigorous searching on eight bibliographic databases. Results were then subject to review using a quality appraisal tool and a narrative synthesis methodology. A theoretical framework was developed for the synthesis using concepts from mental health and communication studies literature.

Results: Systematic searching retrieved 43 original research papers investigating or exploring the effects of online technologies on adolescent mental well-being or related concept(s). The benefits of using online technologies were reported as increased self-esteem, perceived social support, increased social capital, safe identity experimentation and increased opportunity for self-disclosure. Harmful effects were reported as increased exposure to harm, social isolation, depression and cyber-bullying. The majority of studies reported either mixed or no effect(s) of online social technologies on adolescent wellbeing.

Conclusions: This systematic narrative review has revealed contradictory evidence while revealing an absence of robust causal research regarding the impact of social media on mental wellbeing of young people. Online technologies are increasingly being used for health and social care purposes, but further research is required to give confidence that these are appropriately designed to promote the mental health care and support of young people

Keywords: Systematic Narrative Review; Adolescence; Social Networking; Wellbeing; Social Media 


\subsection{Introduction}

The 'science of networks' (Watts, 2007) has evolved significantly over the course of the last decade spurred by the popularity of online communication through social media technology. One group to fully embrace this new medium are young people, with some international data suggesting that $83 \%$ of those aged $18-29$ years use social networking sites (Duggan and Brenner, 2013). Data from the 'EU Kids Online' survey estimates that an average 15 - 16 year old spends 118 minutes per day online (O'Neill et al, 2011). In recognition of the extent of this exposure one must consider the impact of online social media technology is having on young people's psycho-social well-being. Following an advanced systematic database search method, this paper presents a 'narrative review' of research relating to the effects of social media technology (SMT) on adolescent wellbeing to provide a much needed synthesis of current knowledge and a clear direction for future research.

\subsection{Context}

\subsection{Social Media Technology}

Increasingly, academic research has focused on the potential benefits and pitfalls of current technologies, not least in regard to SMT. Of particular interest are social networking sites (SNS) which are defined as "websites which make it possible to form online communities and share user created content" (Kim et al, 2010).

This technology allows for immediate, low cost, private and hidden communication, making it difficult to monitor. Furthermore, it provides the opportunity for both synchronous (immediate) and asynchronous (delayed) communication (Barak, 2007; Stefanone et al, 2011). Positive mental health benefits using SNS's such as increases in social capital via wider social networks have been reported (Ellison et al, 2007), although some studies have highlighted online risks such as cyberbullying, social isolation and exploitation (Kraut et al, 1998; McPherson et al, 2006; Juvonen and Gross; 2008; Milani et al, 2009). Other researchers have avoided this dichotomy between the positives and negatives and have perceived the reality to lie "somewhere between these two extremes" (Bryant et al, 2006).

SNS's however, are only one form of SMT (Moorhead et al, 2013). This distinction is important as individual SMT's have unique features and may influence wellbeing 
differently. This is illustrated when one examines the literature on personality types and online communication whereby both introverts and extraverts may benefit from using SMT's - yet they made choose to use different platforms e.g. introverts may prefer chat rooms (increased anonymity) whereas extraverts may prefer Facebook (Orchard \& Fullwood, 2010; Ryan and Xenos, 2011).

\subsection{Adolescence}

The United Nations Population Fund estimates that there are over 1.8 billion young people aged 10 - 24 in the world today (UN-DESA, 2010), many of whom are facing significant new pressures and challenges due to the increasing demands of modern society (Stengård and Appelqvist-Schmidlechner, 2010). In addition, it has been suggested that children today require more support, training and coping skills to prepare them for a "more complex and technologically advanced society" (Mathur and Freeman, 2002: 695-696). In the midst of such technological advances one must consider the developmental influences these new technologies are having on young people

The creation and maintenance of friendship networks is considered an important and developmentally significant process during adolescence (Hartup, 1996; Strasburger et al, 2009; Manago et al, 2012). During this life stage the peer group often assumes key importance and displaces parental relationships as the principal source of social support for the young person (Coleman, 1974; Boyd and Bee, 2012). Current popular SNS's were launched post 2003 (Boyd and Ellison, 2007) with the result that today's generation of adolescent's are the first cohort to have 'grown up' with online social networking. To date, academic attention in this area appears skewed towards young adult populations, namely older college students (Ellison et al, 2007; Manago et al, 2012). The apparent dearth of research relating to the adolescent age group provided the impetus for the current study and was used to focus on sample populations with a mean age below 20 .

\subsection{Wellbeing}

The term Wellbeing (WB) may be viewed as an abstract and wholly individualised concept whose meaning appears in constant flux. Consequently, it is difficult to operationalize and measure. Research in this field has divided wellbeing into two 
areas; (1) Hedonic and (2) Eudaimonic. Hedonic theorists tend to view wellbeing in a pleasure vs. displeasure paradigm (Ryan and Deci, 2001), with research investigating hedonic wellbeing employing Subjective Well-Being (SWB) as an assessment measure, consisting of the components of life satisfaction, positive affect and negative affect. Eudaimonic psychologists distinguish themselves from the hedonic notion of 'happiness' and measure WB by how one lives and fulfils one's life (Ryff and Keyes, 1995; Ryff and Singer, 2000).

Regardless of WB measure, there appears a strong link between social support and WB. Past studies by both by Argyle (1987) and De Neve (1999) have shown association between wellbeing and high 'relatedness' provided by social networks (Argyle, 1987; DeNeve, 2000). A research review by Nezlek (2000) also concluded that in general those who have greater intimacy and higher quality relationships also have higher wellbeing. The importance of social support networks is further emphasised when one considers the psychological costs associated with the suppression of emotions caused by limited social support (King and Pennebaker, 1998; DeNeve and Cooper, 1998). Cohen and Ashby-Wills (1985) also found evidence of a buffering hypothesis whereby social support mitigates against the full harm of negative life events.

It can be viewed as imperative that the wellbeing consequences of migration towards online social networking (OSN) by the developmentally vulnerable adolescent population is fully investigated and understood. As there is an over-representation of adult sample populations within current research (e.g. undergraduates), the umbrella label of WB, under which a variety of related concept fall, allowed for the inclusion of a sufficient number of studies to warrant a narrative review.

\subsection{Materials and Methods}

This study reviews the evidence regarding the effects of SMT on adolescent wellbeing. The methodological principles upon which this study was developed are influenced by systematic reviewing techniques (Taylor et al, 2007; McFadden et al, 2012) and include seeking transparent and rigorous approaches to identification, quality appraisal and synthesis of studies. At its simplest, systematic reviews are "designed to provide a reliable picture of 'current best evidence' relevant to a particular question" (MacDonald, 2003). While great emphasis is placed on the rigour 
of selection and appraisal methods within such reviews, of equal importance is the methodical quality of data synthesis (Killick and Taylor, 2009). Campbell et al (2003: 5) describes 'synthesis' as "a process of extracting data from individual research studies and interpreting and representing them in a collective form".

In most cases the final product of such reviews is the presentation of a statistical (quantitative) or narrative (qualitative) summary of findings (Rodgers et al, 2009). Due to the nature of the research question and research designs involved within this review a statistical meta-analysis of data was not possible so a narrative review approach to synthesise was used. Narrative reviews may be used to explore studies that investigate:- the effects of interventions; the factors shaping the implementation of interventions; the needs and/or preferences of particular population groups; the causes of particular social and/or health problem (Popay et al, 2006). The methodology of narrative synthesis was informed by the work of Popay and colleagues (2006: 11) who developed an approach involving four specific elements or steps: - (1) Developing a theory of how the intervention works, why and for whom; (2) Developing a preliminary synthesis of findings of included studies; (3) Exploring relationships in the data; (4) Assessing the robustness of the synthesis. The method was further validated in work by Rogers et al (2009) citing how rigorous narrative synthesis approaches added "meaning to quantitative findings". This framework was adopted to reduce bias and to enhance the transparency of the review.

\subsection{Search Strategy}

This study utilised systematic searching techniques to retrieve relevant research studies pertaining to the search topic (McFadden et al, 2012). This was defined as the 'influence of social networking sites on the mental wellbeing of adolescents'. Searches were performed on the following eight bibliographic databases: (1) Applied Social Sciences Index and Abstracts (ASSIA); (2) Communication Abstracts; (3) Cumulative Index to Nursing and Allied Health (CINAHL); (4) Educational Resources Information Centre (ERIC) (5) Medline (Ovid); (6) PsycINFO; (7) Scopus and (8) Social Sciences Citation Index (SSCl) (see figure 1). 
Figure 1. Overview of systematic search strategy

Databases

ASSIA, Communication Abstracts, CINAHL, ERIC, Medline (Ovid SP),

PsycINFO (OVID SP), Scopus and SSCI

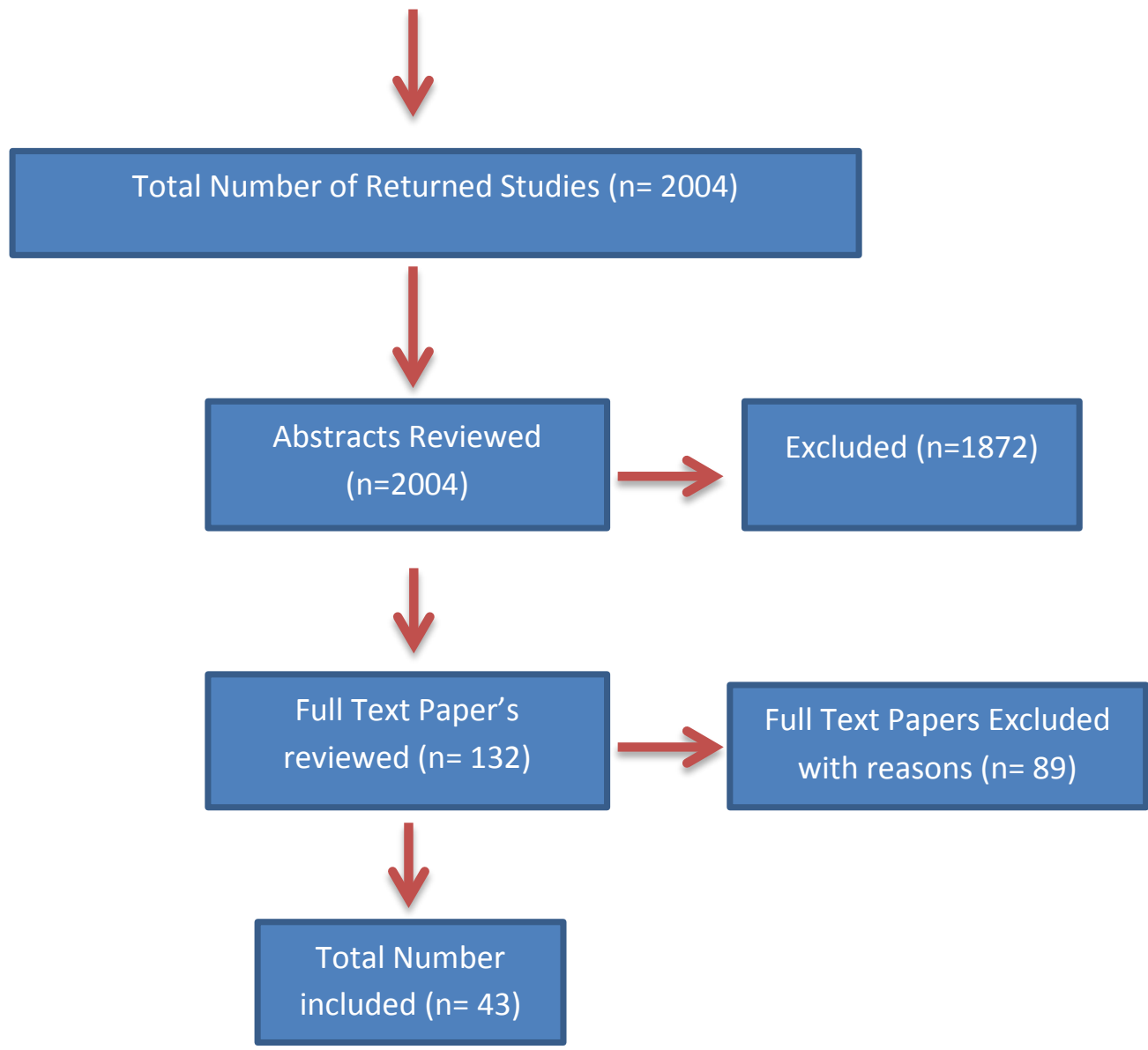

All searches took place within a one week period (11th - 18th April, 2013), each involving up to 41 key words across three concept groups and a pre-defined 'published within' range of $1^{\text {st }}$ January $2003-11^{\text {th }}$ April 2013. The concept groups used to create the search structure were: (1) online social networking; (2) mentalwellbeing and (3) adolescent(s). Figure 2 shows a generic search query used as part of the systematic search process. 
Figure 2: The generic search formula

(Adolescen* OR "Young People" OR Child* OR Youth OR Teen* OR Juvenile)

AND

("Social Media" OR "Online Friends" OR "Online Social Network" OR "Online Social Networking" OR "Online Communities" OR Facebook OR MSN OR Twitter OR Blog OR "Chat Rooms" OR MySpace OR "Online Forum" OR "Net Generation" OR "Digital Natives" OR "Generation Z" OR Cyberspace OR Cyberbullying OR Cyber-bullying OR "Social Networking Sites" OR "Web 2.0")

AND

("Wellbeing" OR "Well-being" OR "Social Support" OR "Perceived Social Support" OR "Mental Health" OR "Self-efficacy" OR "Life Satisfaction" OR "Self-Esteem" OR "Social Capital")

\subsection{Selecting for relevance}

Using pre-defined inclusion criteria, titles and abstracts $(n=2004)$ were reviewed and selected by two members of the research team, with any non-agreement referred to a third reviewer. All included papers had to contain a focus on some form of communicative social media technology. This included blogs, message boards, interactive websites, forums, social networking sites, video sharing platforms (e.g. YouTube) etc. Studies which included samples above 19 years of age were only selected if the mean age was 19 or below. The authors were less prescriptive regarding younger sample populations as they will present with much the same developmental (and generational) vulnerabilities. Grey literature and non-English language papers were excluded due to time and cost constraints. Papers that investigated the impact of the internet were removed unless they included variables relating to interactive online communication with others. A total of 132 studies were identified and subject to full text review. The removal of duplicate studies, theoretical 
material, descriptive case study articles and policy documents produced a final total of 43 original studies presenting empirical research (See Table 2). Using the Kappa statistic, inter-rater reliability between reviewers recorded at 0.82 denoting substantial agreement $(p<0.05)$ (Landis and Koch, 1977).

\subsection{Quality appraisal of studies}

The researchers used the Downs and Black Instrument to appraise methodological quality of quantitative studies (Downs and Black, 1998). This tool is recommended by the Cochrane Collaboration for use with both randomised and non-randomised trials and has been successfully utilised in a recent systematic review of social media within health communication (Downs and Black, 1998; Moorhead et al, 2013). The tool involves questions regarding four key areas (reporting, external validity, internal validity - bias and internal validity - confounding). The total quality score is calculated from questions under these four headings with a maximum score of 32 .

Various tools exist to aid in the appraisal of qualitative research e.g. CASP (Critical Appraisal Skills Programme) and the Quality Framework (Spencer et al, 2003; CASP, 2006). The researchers used both these tools to inform the quality appraisal of qualitative research located within the study. It was recognised that there is less consensus on quality appraisal of qualitative research (Dixon-Woods et al, 2007). With this in mind, the merits of and caveats to each research design were discussed within the research team until consensus was achieved. These tools were used only to assess methodological quality and were not used as a means of synthesis.

\subsection{Synthesis method: Developing a theoretical model for analysis}

Before commencing the narrative review process the authors used the studies themselves to elicit a viable theoretical template to begin the synthesis. Such a method of categorisation has been successfully employed in previous work of a similar nature and scope (Killick and Taylor, 2009). This approach was particularly important in this case as the literature was derived from diverse fields of knowledge and the inter-relationship between studies is less obvious than if there were a consistent frame of reference and terminology across studies. A thematic analysis of each study allowed for a deductive approach to the organisation of key themes and issues. No single theory or model provided the necessary applicability and scope to 
fully categorise the literature. Consequently, a multi-dimensional framework of analysis was developed linking theoretical models from the fields of communication, sociology and psychology. The impact of online social networking among adolescents and the associated nuances is felt throughout the three social levels at macro-, meso- and micro-levels, and a framework at these different levels was developed as described below.

\subsection{Multi-level approaches}

Multi-level approaches are well established within academic literature(s), particularly that of sociology and organisational research (Rousseau, 2011). Simply put, micro level research pertains to individual interactions and processes; macro level research is concerned with wider structural forces and meso research, aptly taken from the Greek word for 'in between' involves group behaviours and processes (House et al, 1995). These paradigms are often used within both quantitative and qualitative research to inform and guide the analytical process. Kozlowski and Klein (2000: 218-220) highlight three broad analytical models present within these approaches:

1. Single level models: Relationships among variables at one level of analysis;

2. Cross level models: Describes the relationship among variables at different levels of analysis; and

3. Homologous multi-level models: Relationships between two or more variables hold at multiple levels of analysis.

\subsubsection{Macro Level: Communication Approaches}

Woodstock (2002) contends that 'communication' is the process through which individuals learn about the world around them. Central to this proposition, is the presence of communication within a context of human interaction and social development (Green et al, 2002; Alder and Rodman, 2006). In fact, some theorists have gone as far as to suggest that inter-personal communication is a key facet of identity formation (Scott, 2007), thus linking communication theory, interpersonal networks and human development. While an uncontested account of 'communication theory' remains to be achieved, what appears clear is that online communication is a 
separate phenomenon with distinguishable characteristics that differentiate it from face to face communication (Walther, 1992). This paper draws upon Shannon and Weaver's (1949) Mathematical Model of Communication to conceptualise this difference (see figure 2).

Figure 3. Shannon and Weaver (1949) Mathematical Model of Communication

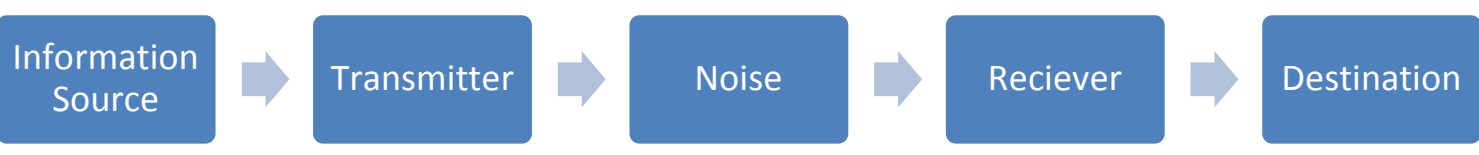

The application of this model to electronic communication has proved particularly valuable and is well established within the communication field. Shannon and Weaver (1949) identify three problems associated with communication; (1) Technical Problems (How accurately can the symbols of communication be transmitted?); (2) Semantic Problems (How do the transmitted symbols convey meaning?); (3) Effectiveness Problems (How effectively do the received meaning affect behaviour).

This tripartite conceptualisation may be applied to the phenomenon of online communication. If one assumes, as mentioned earlier, that individuals learn and develop through the information they receive then any distortion of communication channels may in fact influence and alter behaviour and in turn affect development. This is further supported by Laswell (1948) who notes the crucial determinant of nature of the communication medium (e.g. radio, television, or in this case, the internet etc.) when sharing and receiving information (Walther, 1992). Shannon and Weavers (1949) communication model provides the theoretical framework in which to justify the classification of the literature pertaining to this area

\subsubsection{Meso level: Systems approaches}

A useful starting point for the conceptualisation of a systems based approach is the Aristotelian view that "the whole is more than the sum of its parts" (von Bertalanffy, 1962; 1972). In a general sense, a system may be defined as a "group of objects related or interacting so as to form a unity" (Garmonsway, 1991). A network is 
described as a "group of persons sharing an aim or interest and frequently communicating with...or helping each other (Garmonsway, 1991). Social systems and networks involve interaction(s) and transaction(s) among a collective which may influence or alter the behaviour of individuals. Ecological Systems theory adds a humanistic feature to general system-based theories and is concerned mainly with interactions between individuals within a social system (Siporin, 1980). Furthermore, Ecological Systems Theory provides a framework in which to understand human development within an environmental context (Bronfenbrenner, 1979; 1986; 1989; Miller, 2011). A meso level approach allows one to examine online group behaviours and processes, with a particular focus on the development and maintenance of adolescent social networks.

\subsubsection{Micro level: Adolescent development approaches}

Following on from communication and systems based approaches is a focus on the impact of SMT's on the individual. Thematic analysis suggested that macro/meso theories interact at this point through developmental issues unique to this population. Theories regarding human development and wellbeing are a plenty within the psychological literature. In specific regard to adolescence, (and although somewhat incongruent) theories such as those offered by Sigmund Freud, Piaget and Erik Erikson define human development sequentially postulating responses to external stimuli determined by developmental stage (Bronfenbrenner, 1979).

Erikson's (1968) 'Stages of Psycho-social Development' posits adolescent development occurring primarily through identity formation within the context of social relationships (Moshman, 1999). The successful transition of each life stage in Erikson's model is presented as a 'crisis' (e.g. identity vs. confusion) through which one must negotiate in order to progress. There is a period of instability before adolescent identity and positive self-esteem are achieved (Erikson, 1968). It can be seen that psychological and physiological changes cause vulnerability as coping mechanisms are constantly redefined (Frydenberg, 2008), therefore challenges, stressors or threats could have exacerbated affects (Manago et al, 2012). Erikson's model provides a theoretical framework in which to explore issues such as selfesteem, belonging and identity (Erikson, 1968). Additional models of adolescent development are offered by Steinberg and colleagues (2005) whereby adolescence 
is seen as divided into three distinct stages (Early, Middle and Late Adolescence) each of which poses differing vulnerabilities and risks (Steinberg, 2005).

\subsection{Results}

\subsection{Methodological profile and quality of included studies}

The research methodologies of studies investigating the influence of social networking sites on the mental wellbeing of adolescents were varied. The majority of studies (95\%) had gender-mixed samples. However many studies had a higher number of female participants. Survey research (55\%) was by far the most widely employed research design, followed by qualitative (12\%), longitudinal (12\%), content analysis (11\%), experimental (4\%), case control (3\%) and mixed method studies (3\%). The quantitative studies $(n=32)$ evaluated using the Downs and Black Instrument had scores ranging from 8 (O'Dea and Campbell, 2011) to 20 (DolevCohen and Barak, 2013). These low scores reflected the weak nature of research designs retrieved within the study in relation to the research question.

Table 1. List of studies by general methodology

\begin{tabular}{|l|l|l|}
\hline Quantitative = 32 & Qualitative = 9 & Mixed/Other \\
\hline Gross, 2004 & Tichon and Shapiro, 2003 & Valaitis, 2005 \\
Donchi and Moore, 2004 & Thomas, 2006 & Nicholas, 2010 \\
Valkenburg et al, 2006 & Williams and Merten, 2008 & \\
Van den Ejinden, 2008 & Cerna and Smahel, 2009 & \\
Hwang et al, 2009 & Siriaraya et al, 2011 & \\
Ko and Kuo, 2009 & Duggan et al, 2012 & \\
Maarten et al, 2009 & Davies, 2012 & \\
Gross, 2009 & Parris et al, 2012 & \\
Lee, 2009 & Cash et al, 2013 & \\
Baker and White, 2010 & & \\
Wilson et al, 2010 & & \\
Tomai et al, 2010 & & \\
Leung, 2011 & & \\
Vandoninck et al, 2011 & & \\
O'Dea and Campbell(1), 2011 & & \\
O'Dea and Campbell(2), 2011 & & \\
Pantic et al, 2012 & & \\
Devine and Lloyd, 2012 & & \\
\hline
\end{tabular}




\begin{tabular}{|l|l|l|}
\hline Fioravanti et al, 2012 & & \\
Jelenchick, 2012 & & \\
Koles and Nagy, 2012 & & \\
Huang and Leung, 2012 & & \\
Sarriera et al, 2012 & & \\
Ahn, 2012 & & \\
Fanti et al, 2012 & & \\
Machmutow et al, 2012 & & \\
Quinn and OldMeadow, 2013 & & \\
Vandoninck et al, 2013 & & \\
Apaolaza et al, 2013 & \\
Sticca et al, 2013 & \\
Pea et al, 2012 & \\
Dolev-Cohen and Barak, 2012 & & \\
\hline
\end{tabular}

\subsection{Communication-based approaches}

Research in this category fell into five broad areas: (1) intensity of online communicative practices; (2) preference for online communication; (3) online disclosure processes and motivations; (4) behaviour change through online communications; and (5) differences associated with online and offline communications. The rise of the internet and social networking sites has seen the rapid growth of readily available and accessible information on the social habits of individuals. Qualitative content analysis of publicly available profile pages, message boards and blogs has been readily employed within this area (Cerna and Samhel, 2009; Duggan et al, 2011; Siriaraya et al, 2011; Williams and Merten, 2013; Cash et al, 2013). Such studies suggest a 'treasure trove' of information available online regarding the communication patterns and social lives of adolescents. The literature suggests teens are more willing to disclose personal information online and, in general, displayed more emotionally empathic online communication than adults (Tichon and Shapiro, 2003; Cerna and Samhel, 2009; Ko and Kuo, 2009; Duggan et al, 2011; Siriaraya et al, 2011; Cash et al, 2013). As a result, a growing body of evidence is emerging examining the potential role of supportive virtual environments for young people (Tichon and Shapiro, 2003; Ko and Kuo, 2009; Cerna and Samhel, 2009; Nicholas, 2010; Dolev-Cohen and Barak, 2013; Siriaraya et al, 2011). 
Considerable evidence suggests a negative relationship between online communication practices and wellbeing (Van den Eijnden et al, 2008; Hwang et al, 2009; O'Dea and Campbell, 2011;; Devine and Lloyd, 2012; Fioravanti et al, 2012;, Pantic et al, 2012; Koles and Nagy, 2012). Evidence of a 'rich-get-richer' phenomenon is provided whereby young people whose offline friendship quality is perceived as 'high' had greater benefits from online communicative activities those who did not possess high quality friendships (Ko and Kuo, 2009; Maarten et al, 2009; Davis, 2012). Perhaps reflecting the division of opinion in this field a number of studies reported positive affect between online communication and wellbeing, namely; increased social support, reduced social anxiety, increased self-esteem and reduced social isolation (Ko and Kuo, 2009; Gross, 2009; Maarten et al, 2009; Valkenburg et al, 2009; Davis, 2012; Dolev-Cohen and Barak, 2013). Moreover, three papers highlighted the possible mental health promotion benefits of online communication (Valaitis, 2005; Cerna and Smahel, 2009; Frydenberg, 2008) and interestingly, two studies reported little or no association between online communication and depression among adolescents (Gross, 2004; Jelenchick et al, 2013).

\subsection{Social network and system based approaches}

A number of studies examined the WB implications of SMT through the lens of interpersonal relationship formation, online friendships, social capital and social support (see below). These studies were categorised under the umbrella of social network and system based approaches and their underpinnings allowed an examination of the impact of OSN on social network development and the possible implications for individual wellbeing.

An emerging theme within the literature was online friendship (or related concept) (Tichon and Shapiro, 2003; Donchi and Moore, 2004; Hwang et al, 2009; Maarten et al, 2009; Davis et al, 2012; Fanti et al, 2012; Quinn and Oldmeadow, 2012; Apaolaza, 2013; Dolev-Cohen and Barak, 2013). However, a precise definition of what constitutes an 'online friend' was somewhat illusive. Some suggest that online friends are merely an extension of offline relationships (Gross, 2004; Thomas, 2006; Ahn, 2012), perhaps minimalizing any differentiating factors, making separate definition(s) problematic. The purported benefits of online friendships were identified 
as the following: increased perceived social support; opportunity for emotional relief; increased social integration; opportunity for identity experimentation and extended 'bridging' social capital (i.e. wider social connections outside local networks, see Putnam, 2000) (Ko and Kuo, 2009; Ahn, 2012; Lueng, 2011; Sarriera, et al, 2012; Dolev-Cohen and Barak, 2013).

Social support offered through social networking sites, blogs, and specialist forums etc. provided a number of specific benefits such as increased emotional support, self-disclosure, reduced social anxiety and belongingness (Tichon and Shapiro, 2003; Valaitis, 2005; Ko and Kuo, 2009, Duggan et al, 2011; Siriaraya et al, 2011; Quinn and Oldmeadow, 2012; Williams and Merten, 2013). However, one study of online self-harm websites highlighted the lack of 'trigger warnings' within informal support forums/websites compared to their professional counterparts, indicating increased risk associated with the use of the former (Duggan et al, 2011). Moreover, some informal websites were also found to promote negative attitudes, actively discouraging professional help seeking (Cerna and Smahel, 2009).

Two studies compared wellbeing through communicative online activities with noncommunicative activities, finding communicative online activities positively associated with increases in wellbeing (Hwang et al, 2009; Maarten et al, 2009). Social networking sites have been linked with community formation and increased belongingness among adolescents (Quinn and Oldmeadow, 2012). Social capital benefits, in particular bridging capital, are also evident within the literature, indicating a link between online networking and offline gains (Tomai et al, 2010; Ahn, 2012). Interestingly, one study also found evidence of increasing bonding capital as online usage increased (Tomai et al, 2010).

\subsection{Adolescent development approaches}

Eight studies used measures of self-esteem in relation to SMT (Valkenburg and Peter, 2006; Gross, 2009; Wilson et al, 2010; Baker and White, 2011; O'Dea and Campbell, 2011; Firoravanti et al, 2012; Huang and Leung, 2012; Apaolaza et al, 2013). Three reported associations between SMT, blogging and low self-esteem (Maarten et al, 2009; Firoravanti et al, 2012; Huang and Leung, 2012). Conversely, positive self-esteem associations were found between online communicative activities such as online chatting with peers or strangers or receiving support when 
distressed (Donchi and Moore, 2004; Valkenburg and Peter, 2006, Gross, 2009). Self-esteem was examined as a predicting factor of levels of social networking site usage in two studies but neither reported a significant relationship (Wilson et al, 2010; Baker and White, 2011).

Mixed results were reported in studies examining depression and SMT's (Van den Eijnden, 2008; Pantic et al, 2012; Vandoninck et al, 2012; Jelenchick et al, 2013). For example, instant messenger has been linked with increased depression in one study (Van den Eijnden, 2008) yet equally other evidence suggested no such relationship (Jelenchick et al, 2013). One large scale Taiwanese study found increased depressive mood among adolescents who used the internet to socialise and make friends, but no significant association was found between the amount of time spent online and depression (Vandoninck et al, 2011). More generally, a number of studies in North America have found negative associations between 'social wellbeing' and interpersonal interaction online (Pea et al, 2012).

Five studies collected data on loneliness or related concepts (e.g. social isolation) and SMT (Donchi and Moore, 2004; Gross, 2004; Leung, 2011; Huang and Leung, 2012; Apaolaza et al, 2013). In some cases loneliness decreased following OSN (Gross, 2009; Jelenchick et al, 2013). However, in one study this association was only significant for females (Apaolaza et al, 2013). Online social interaction has also been shown to support identity experimentation and found to be a more gratifying experience for lonely adolescents (Leung, 2011). Indeed further evidence from a Chinese study on bulletin board systems suggests a preference for OSN among lonely adolescents (Jelenchick et al, 2013). Related to this were two further studies which investigated feelings of belongingness (Quinn and Oldmeadow, 2012) and social exclusion (Thomas, 2006) amongst online users. Both reported positive effects between OSN and increased belongingness and reduced isolation.

\subsection{Cyber-bullying (CB)}

While cyber-bullying (CB) is emerging as a separate field of research in its own right, it was considered for the purposes of this review that $\mathrm{CB}$ is a relevant mental wellbeing issue occurring exclusively via social media and other online interactive technologies. CB is described as a "wilful and repeated harm inflicted through the use of computers...and other electronic devices" (Hinduja and Patchin, 2010). Four 
papers were recovered which focused on CB (Fanti et al, 2012; Machmutow et al, 2012; Parris et al, 2012; Sticca et al, 2012) however all varied dramatically in nature and scope. Collectively, their findings suggest that offline social support may buffer the negative impact of CB (Parris et al, 2012); that time spent online may increase risk of CB (Machmutow et al, 2012); that CB (victimisation and offending) may be predicted using Psychopathic Trait measures (Sticca et al, 2012) and that victims often adopt three main attitudes strategies to reduce the impact of $C B$ - reactive coping (responding after the event); preventative coping (protection measures e.g. stay offline) and/or acceptance (Parris et al, 2012).

Table 2. Mental well-being and related concepts by study

\begin{tabular}{|c|c|}
\hline Study & $\begin{array}{l}\text { Wellbeing Issue or related concept } \\
\text { investigated }\end{array}$ \\
\hline Tichon and Shapiro, 2003 & Social Support \\
\hline Gross, 2004 & Social Isolation/Social Anxiety \\
\hline Donchi and Moore, 2004 & Self-Esteem/Loneliness \\
\hline Valaitis, 2005 & Social participation/risk/ increased reflection \\
\hline Valkenburg et al, 2006 & Self-Esteem/Wellbeing \\
\hline Thomas, 2006 & Identity Formation/development \\
\hline Williams and Merten, 2008 & 'Risk Behaviours' \\
\hline Van den Ejinden, 2008 & Loneliness \\
\hline Hwang et al, 2009 & Depressive Mood \\
\hline Ko and Kuo, 2009 & Subjective Well-being \\
\hline Maarten et al, 2009 & Depression and Anxiety \\
\hline Gross, 2009 & Social Exclusion \\
\hline Cerna and Smahel, 2009 & Social Support \\
\hline Lee, 2009 & Healthy Social Relationships (Parental and Peer) \\
\hline Baker and White, 2010 & Self-Esteem Measure \\
\hline Wilson et al, 2010 & Self-Esteem/Personality \\
\hline Tomai et al, 2010 & Social Capital \\
\hline Nicholas, 2010 & Online Mental Health Support \\
\hline Leung, 2011 & Loneliness/Social Support \\
\hline Vandoninck et al, 2011 & 'Psycho-social factors' \\
\hline O'Dea and Campbell(1), 2011 & Self-Esteem/Social Support \\
\hline O'Dea and Campbell(2), 2011 & 'Peer Support' \\
\hline Siriaraya et al, 2011 & 'Emotional Support' \\
\hline Pantic et al, 2012 & Depression \\
\hline
\end{tabular}




\begin{tabular}{|l|r|}
\hline Duggan et al, 2012 & Non-Suicidal Self-Harm \\
Devine and Lloyd, 2012 & Psychological WB \\
Fioravanti et al, 2012 & Self-Esteem \\
Jelenchick, 2012 & Depression \\
Koles and Nagy, 2012 & 'Emotional Support' \\
Huang and Leung, 2012 & Self-Esteem/Loneliness \\
Pea et al, 2012 & Social Wellbeing \\
Sarriera et al, 2012 & Personal Wellbeing \\
Ahn, 2012 & Social Capital \\
Fanti et al, 2012 & Bullying/Social Support \\
Dolev-Cohen and Barak, 2012 & Emotional State/Personality \\
Davies, 2012 & Identity/friendship \\
Parris et al, 2012 & Cyber-Bullying \\
Machmutow et al, 2012 & Cyber-Bullying \\
Quinn and OldMeadow, 2013 & 'Belonging' \\
Vandoninck et al, 2013 & Self-Efficacy \\
Apaolaza et al, 2013 & Sulcide disclosure \\
Cash et al, 2013 & Self-Esteem/Loneliness \\
Sticca et al, 2013 & Cyber-Bullying/Self-Esteem \\
\hline
\end{tabular}

\subsection{Discussion}

This study seeks to build upon the high quality methodology of studies such as Moorhead et al (2013) and takes the topic of social media usage a step further by focusing on a more precise domain within the field of adolescent health and development. As part of a narrative review method, a theoretical model to assist with preliminary analysis was developed. Following on, the final two stages were to (1) explore relationships within the data and (2) assess the robustness of the synthesis (Popey et al, 2006).

\subsection{Exploring relationships: Benefits vs. limitations of online social networking}

Perhaps surprising, given the growing academic and public concern, the majority of included papers reported either mixed or no effect(s) of social media on adolescent wellbeing (Gross, 2004; Valkenburg and Peter, 2006; Cerna and Smahel, 2009; Lee, 2009; Wilson et al, 2010; Baker and White, 2011; Leung, 2011; Fanti et al, 2012; Parris et al, 2012; Sarriera et al, 2012; Sticca et al, 2012; Vandoninck et al, 2012; Cash et al, 2013; Jelenchick et al, 2013; Vandoninck et al, 2013; Williams and 
Merten, 2013). These included studies which found no association(s) between SMT's and wellbeing concepts (e.g. depression) as well as those who uncovered both increased opportunities and increased risks for wellbeing from OSN (Valkenburg and Peter, 2006; Jelenchick et al, 2013; Vandoninck et al, 2013).

\subsection{Benefits of online social networking}

Following the review process, 13 of the 43 studies were deemed to report beneficial outcomes regarding SMT and communication. By and large, these benefits were indirect and fuelled by perceptions regarding perceived social support. For example, increased social networking opportunities raise self-esteem and 'belongingness' which may then indirectly impact upon feelings of wellbeing. However, it is worth cautioning that perceived online social support may be providing a false sense of security. To balance this concern, considerable evidence suggested direct emotional and empathetic support via online networks can contribute to lowering barriers to self-disclosure (Ko and Kuo, 2009), through increased anonymity and reduced nonverbal inhibitors, thus promoting the help-seeking process. In turn, self-disclosing and associated positive feedback can enhance perceptions of community integration (Ko and Kuo, 2009) and social support (Davies, 2012; Quinn and Oldmeadow, 2013). These processes may provide a more direct explanatory link between SMT and increased wellbeing. Moreover, it is likely that repressing emotions through nondisclosure will have a negative impact upon wellbeing (Dolev-Cohen and Barak, 2013). Online disclosure can benefit stigmatised groups facilitating and encouraging their contact with mental health resources. This technology may also appeal to young males as a more fashionable alternative to traditional forms of help seeking.

\subsection{Caveats to online social networking}

A variety of negative outcomes between SMT and wellbeing is present within the literature. Informed by the theoretical model one could suggest that, by and large, these studies view online communication as a weaker form of interaction - the cost of which could be increased risk of depression and/or social isolation. There was evidence of links between preferences for social interaction, friendship formation online and decreases in wellbeing, however little if any association was found between number of online friends and lower wellbeing. 
One large scale study suggests that merely having a social networking profile may decrease psychological wellbeing; however this negative relationship was reported only for girls (Devine and Lloyd, 2012). An important link within the body of research reviewed is the association between increased intensity of usage i.e. time spent online and increased risk of exposure to online harm, particularly pertinent to risk of CB. CB has been associated with increased depression and is therefore a real risk to adolescent wellbeing. In spite of these possibilities, little direct or indirect associations were found between time spent online and negative wellbeing, save for one Serbian study (Pantic et al, 2012). Research is thus moving away from variables relating to intensity of use, and is shifing towards the impact of different and discrete online activities.

\subsection{Future Directions}

The findings from this review indicate that SMT's allow adolescents to increase the size and composition of their social networks substantially. This may be either beneficial (e.g. increased social capital, social support etc.) or harmful through increased exposure to triggering or abusive content or the promotion of negative coping strategies (Duggan et al, 2011).

One key factor associated with wellbeing outcomes, was the use of online technologies for communicative rather than non-communicative purposes (Vandoninck et al, 2011). SMT's which promote communicative activities were shown to provide more wellbeing benefits; however this must be tempered with the fact that such activities may also increase exposure to harm. Consequently, strategies to support the wellbeing of young people who use SMT's may wish to focus on the following areas; (1) the particular SMT being used; (2) the communicative and non-communicative activities that are taking place and (3) the social capital available to that individual to manage the potentially negative experiences that may arise. In regards to the latter, one must consider the wider social network as an important factor as they provide the context to which negative encounters are experienced. Again, the actual SMT being used is of great importance as different SMT's provide different social networking contexts (e.g. Facebook vs. Askfm). Future research may wish to explore these issues in more 
depth as well as consider the differing motivations (e.g. personality types) behind social media usage and the subsequent wellbeing implications.

\subsection{Robustness and limitations of the synthesis}

In terms of overall methodological quality, there was an over-representation of crosssectional survey based research, recognised as a weaker research design in relation to the research question, for which experimental designs are notably stronger. In the face of such evidence, one is unable to distinguish various mitigating factors such as gender, socio-economic status, geographical locality etc. on adolescent OSN and wellbeing much less the impact of online friendships or specific online activities. Moreover, a disparity exists between both inductive and deductive approaches within the evidence base, therefore a greater number of mixed method designs would be welcomed within the literature. As the quality of included studies will undoubtedly impact on the reliability of the synthesis drawn from it, one must highlight this limitation. Popey et al (2006) intimate this restriction can be avoided if steps are taken to critically review the methodological quality of each study and thus ensure appropriate 'weighting'. Using a validated instrument such as Downs and Black (1998) enables researchers to strengthen synthesis reliability. The systematic search of online databases has proved a useful formula for locating research on the topic however; future research may wish to expand the range of databases further to include more specialist communication focused databases.

\subsection{Conclusion and Future Directions}

This review has classified research findings in terms of the influence of social media on adolescent wellbeing. However, it must be recognised that technology acts merely as a facilitator of human interaction and is value-free, neither promoting the good nor the bad. Retrieved within this review was a wealth of contradictory evidence suggesting both harmful and beneficial aspects of SMT's. However, one must point to a lack of evidence exacting the specific direction of the relationship between SMT and wellbeing. Be that as it may, a growing body of evidence is suggesting that SMT and WB experience(s) (either positive or negative) are premised upon specific online activity rather than variables such as, the 'amount of time' or 'number of online friends'. This would suggest that early education of children and adolescents on the various pitfalls of SMT's may enable them to avoid 
more 'harmful' activities e.g. talking to strangers and thus reduce harmful experience(s).

Of further interest is the ability of SMT's to foster self-disclosure through increased social network size and composition. This may prove valuable to health and social care professionals attempting to access traditionally hard-to-reach populations such as, young males or those experiencing mental ill-health. Future studies may wish to include the benefits of both informal and formal means of online support. Little or no association was found between the number of online friends and WB, perhaps suggesting more indirect effect(s) or a current indistinguishable 'merging' between online and offline social networks. Further research would therefore do well to investigate the impact of online friendships on issues such as online help-seeking, exposure to harm, cyber-bullying etc. 


\section{References}

Adler, R, B., and Rodman, G. (2006). Understanding Human Communication, (9th Edition), New York, Oxford, Oxford University Press.

Ahn, J. (2012). "The effect of social network sites on adolescents' social and academic development: Current theories and controversies", Journal of the American Society for Information Science \& Technology, 62(8), 1435-1445.

Apaolaza, V., Hartmann, P., Medina, E., Barrutia, J., and Echebarria, C. (2013) The relationship between socializing on the Spanish online networking site Tuenti and teenagers' subjective wellbeing: The roles of self-esteem and loneliness. Computers in Human Behavior, 29, 4

Argyle M. (1987). The Psychology of Happiness. London: Methuen

Baker, R.K. \& White, K.M. 2011, "In their own words: why teenagers don't use social networking sites", Cyberpsychology, Behavior And Social Networking, 14(6) 395398.

Barak, A. (2007). "Emotional support and suicide prevention through the Internet: A field project report". Computers in Human Behavior, 23(2), 971-984, doi:10.1016/j.chb.2005.08.001

Boyd, D, R and Bee H, L. (2012). Lifespan Development (6th ed.). Pearson/Allyn and Bacon. Boston.

Boyd, D, M and Ellison N, B (2007). Social network sites: Definition, history and scholarship. Journal of Computer-Mediated Communication 13(1): 210-230. doi:10.1111/j.1083-6101.2007.00393.x

Bronfenbrenner, U. (1979). The Ecology of Human Development: Experiments by Nature and Design. Cambridge, MA: Harvard University Press. ISBN 0-674-22457-4

Bronfenbrenner, U. (1986). The ecology of the family as a context for human development. Developmental Psychology, 22, 723-742. 
Bronfenbrenner, U. (1989). Ecological systems theory. In R. Vasta (Ed.), Six theories of child development: Revised formulations and current issues. 185-246. Greenwich, CT. JAI Press.

Bryant, J. A., Sanders-Jackson, A., \& Smallwood, A. M. K. (2006). IMing, text messaging, and adolescent social networks. Journal of Computer-Mediated Communication, 11(2). doi:10.1111/j.1083-6101.2006.00028.x

Campbell, R., P. Pound, C. Pope, N. Britten, R. Pill, M. Morgan and J. Donovan (2003) 'Evaluating Meta-Ethnography: A Synthesis of Qualitative Research on Lay Experiences of Diabetes and Diabetes Care', Social Science and Medicine 56: 67184.

Cash S, Thelwall M, Peck S, Ferrell J, Bridge J. (2013) Adolescent suicide statements on MySpace. Cyberpsychology, Behavior, and Social Networking, 16:166-174.

CASP (2006). Qualitative research: appraisal tool. 10 questions to help you make sense of qualitative research. In. Oxford: Public Health Resource Unit. 1-4. Available from: www.phru.nhs.uk/Doc Links/Qualitative Appraisal Tool.pdf

Cerna, A. and Smahel, D. (2009). Self-injury in adolescence: Blog as a mean of community formation. Ceskoslovenska Psychologie, 53(5): 492-504.

Cohen, S and Ashby Wills, T. (1985). Stress, Social Support and the Buffering Hypothesis. Psychological Bulletin. 92(2), 310 - 357

Coleman, J. (1974). Relationships in Adolescence. Routledge and Kegan Paul. London.

Davis, K. (2012). Friendship 2.0: Adolescents' experiences of belonging and selfdisclosure online. Journal of Adolescence, 35 (6), 1527-1536.

DeNeve KM, Cooper H. (1998). The happy personality: a meta-analysis of 137 personality traits and subjective well-being. Psychological Bulletin, 124, 197-229. doi: $\underline{10.1037 / 0033-2909.124 .2 .197}$ 
DeNeve, K, M. (1999). Happy as an extraverted clam? The role of personality for subjective well-being. Current Directions in Psychological Science, 8, 141-44. doi: $10.1177 / 1359105308093860$

P. \& Lloyd, K. (2012). "Internet use and psychological well-being among 10-year-old and 11-year-old children.", Child Care in Practice, 18(1) 5-22.

Dixon-Woods, M., Booth, A., \& Sutton, A.J. ( 2007). Synthesizing qualitative research: A review of published reports. Qualitative Research, 7, 375-422. doi:10.1177/1468794107078517

Donchi, L. \& Moore, S. (2004). "It's a boy thing: The role of the Internet in young people's psychological wellbeing", Behaviour Change, 21(2), 76-89.

Dolev-Cohen, M Barak, A (2013). Adolescents' use of Instant Messaging as a means of emotional relief. Computers in Human Behavior, 29(1) 58-63

Downs, S, H., Black, N. (1998). The feasibility of creating a checklist for the assessment of the methodological quality both of randomised and non-randomised studies of health care interventions. Journal of Epidemiology \& Community Health [doi: 10.1136/jech.52.6.377]

Duggan, J.M., Heath, N. L., Lewis, S. P., \& Baxter, A. (2011). An examination of the scope and nature of non-suicidal self-injury online activities: Implications for school mental health professionals. School Mental Health, 4, 56-67. doi: 10.1007/s12310011-9065-6

Duggan, M., and Brenner, J. (2013). The Demographics of Social Media Users. Pew Internet Research Centre's Internet and American Life Project. http://pewinternet.org/Reports/2013/Social-media-users.aspx

Ellison, N.B., Steinfield, C., \& Lampe, C. (2007). The Benefits of Facebook "Friends:" Social Capital and College Students' Use of Online Social Network Sites. Journal of Computer-Mediated Communication. 1143-1168. DOI: 10.1111/j.1083$\underline{6101.2007 .00367 . x / \text { CrossRef link }}$

Erikson, Erik H. (1968). Identity, Youth and Crisis. New York: Norton. 
Fanti, K.A., Demetriou, A.G. \& Hawa, V.V. (2012) "A longitudinal study of cyberbullying: Examining risk and protective factors", European Journal of Developmental Psychology, vol. 9, no. 2, pp. 168-181.

Fioravanti, G., Dèttore, D., Casale, S. (2012) Adolescent Internet Addiction: Testing the Association Between Self-Esteem, the Perception of Internet Attributes, and Preference for Online Social Interactions. Cyberpsychology, Behavior, and Social Networking 15(6): 318-323. doi:10.1089/cyber.2011.0358

Frydenberg, E. (2008). Adolescent Coping: Advances in Theory, Research and Practice. Routledge, New York.

Garmonsway, G.N., (1991). The Penguin Concise English dictionary. Harmondsworth, Middlesex, England: Penguin Books,

Green, M, C., Strange, J, J., and Brocks, T, C. (2002). Narrative Impact: Social and Cognitive Foundations, Hillsdale, NJ, Lawrence Erlbaum Associates, 287-314.

Granovetter, M. (1973) The Strength of Weak Ties. American Journal of Sociology, 78(6), $1360-1380$.

Gross, E.F. (2004). "Adolescent internet use: What we expect, what teens report", Journal of Applied Developmental Psychology, 25(6), 633-649.

Gross, E.F. (2009). Logging on, bouncing back: An experiential investigation of online communication following social exclusion. Developmental Psychology, 45, 1787-1793.

Hartup, W, W. (1996). The company they keep: Friendships and their developmental significance. Child Development, 67, 1-13 doi: 10.1037/0012-1649.36.3.326

Hinduja, S. \& Patchin, J. W. (2010). Bullying, cyberbullying, and suicide. Archives of Suicide Research, 14 (3), 206-221

House, R., Rousseau, D. M., \& Thomas, M. 1995. MESO: An integration of macro and micro Organizational Behavior. In L. L. Cummings \& B. M. Staw (Eds.), Research in organizational behavior, 17, 71-114. Greenwich, CT: JA 
Huang, H. Y. \& Leung, L. (2012). Gratification-opportunities, Self-esteem, and Loneliness in Determining Usage Preference of BBS and Blog among Teenagers in China. Atlantic Journal of Communication, 20(3): 141-157.

Hwang, J.M., Cheong, P.H. \& Feeley, T.H. (2009). "Being young and feeling blue in Taiwan: examining adolescent depressive mood and online and offline activities", New Media \& Society,11(7), 1101-1121.

Jelenchick L.A, Eickhoff J.C, Moreno M.A. (2013) Facebook depression?" social networking site use and depression in older adolescents. Journal of Adolescent Health52(1):128-30. doi: 10.1016/j.jadohealth.2012.05.008

Juvonen, J., \& Gross, E. F. (2008). Extending the school grounds?-Bullying experiences in cyberspace. Journal of School Health, 78(9), 496-505. doi: 10.1111/j.1746-1561.2008.00335.x.

Killick, C., and Taylor B, J. (2009). Professional decision making on elder abuse: Systematic narrative review. Journal of Elder Abuse and Neglect, 21, 211-238. doi:10.1080/08946560902997421

Kim, W., Jeong, O., \& Lee, S. (2010). On social web sites. Information Systems, 35(2), 215-236. doi:10.3846/bm.2012.120

King, L, A., and Pennebaker, J, W. (1998). What's so great about feeling good? Psychological Inquiry, 9, 53-56. doi: 10.1037/0022-3514.79.4.617

Ko and Kuo, (2009). Can blogging enhance subjective well-being through selfdisclosure? CyberPsychology \& Behavior. 12(1): 75-79. doi:10.1089/cpb.2008.016.

Koles, B. \& Nagy, P. (2012), "Facebook usage patterns and school attitudes", Multicultural Education and Technology Journal, 6(1), 4-17.

Kozlowski, S. W. J., \& Klein, K. L. (2000). A multilevel approach to theory and research in organizations: Contextual, temporal, and emergent processes. In K. J. Klein \& S. W. J. Kowlowski (Eds.), Multilevel theory, research, and methods in organizations (pp. 3-90). San Francisco: Jossey-Bass.

Kraut, R., Patterson, M., Lundmark, V., Kiesler, S., Mukopadhyay, T., \& Scherlis, W. (1998). Internet paradox: A social technology that reduces social involvement and 
psychological well-being? American Psychologist, 53, 1017-1031. doi: 10.1037/0003-066X.53.9.

Landis JR, and Koch GG. (1977). The measurement of observer agreement for categorical data. Biometrics. 33, 159-174

Laswell, M. (1948) 'The Structure and Function of Communication in Society' in L. Bryson (ed). The Communication of Ideas. New York: Institute for Religious and Social Studies.

Lee, S.J. (2009), "Online communication and adolescent social ties: Who benefits more from Internet use?", Journal of Computer-Mediated Communication,14(3), 509531.

Leung, L. (2011) "Loneliness, social support, and preference for online social interaction: the mediating effects of identity experimentation online among children and adolescents", Chinese Journal of Communication, 4(4)

Maarten H.W. Selfhout, Susan J.T. Branje, M. Delsing, Tom F.M. ter Bogt,Wim (2009).Different types of Internet use, depression, and social anxiety: The role of perceived Friendship Quality, Journal of Adolescence, 32(4), 819-833.

MacDonald, G. (2003) Using Systematic Reviews to Improve Social Care, London, Social Care Institute for Excellence.

Machmutow, K., Perren, S., Sticca, F., \& Alsaker, F. D. (2012). Peer victimisation and depressive symptoms: Can specific coping strategies buffer the negative impact of cybervictimisation? Emotional and Behavioral Difficulties, 17(3), 403-420.

Manago, A.M., Taylor, T. \& Greenfield, P.M. (2012). "Me and my 400 friends: The anatomy of college students' Facebook networks, their communication patterns, and well-being.", Developmental psychology, 48(2) 69-380. doi: 10.1037/a0026338

Mathur, V, K and Freeman, D, G. (2002) A theoretical model of adolescent suicide and some evidence from US data. Health Economics. 11: 695-708

McFadden, P., Taylor, B.J., Campbell, A. and McQuilkin, J. (2012) Systematically identifying relevant research: Case study on child protection social workers' 
resilience. Research on Social Work Practice, 22(6), 626-636. doi: 10.1177/1049731512453209.

McPherson, M., Smith-Lovin, L. \& Brashears, M. E. (2006). Social isolation in America, American Sociological Review, 71(3), 353-375. doi: $10.1177 / 000312240607100301$

Milani, L., Osualdella, D., \& Di Blasio, P. (2009). Quality of interpersonal relationships and problematic Internet use in adolescence. CyberPsychology \& Behavior, 12, 681-684. doi:10.1089/cpb.2009.0071

Miller, P, H. (2011) Theories of Developmental Psychology, 5th Edition. Worth Publishers: New York.

Moorhead, S, A., Hazlett, D, E., Harrison, L., Carroll, J, K., Irwin, A., Hoving, C., (2013). A new dimension of Health Care: Systematic Review of the Uses, Benefits and Limitations of Social Media for Health Communication. Journal of Medical Internet Research, 15(4) e85

Moshman, D. (1999) Adolescent Psychological Development: Rationality, Morality and Identity. Lawrence Erlbaum Associates: London

Nezlek, J, B. (2000). The motivational and cognitive dynamics of day-to-day social life. In The Social Mind: Cognitive and Motivational Aspects of Interpersonal Behaviour, ed. J, P., Forgas, K., Williams., L Wheeler, 92-111. New York: Cambridge Univ. Press

Nicholas, J. (2010). The role of internet technology and social branding in improving the mental health and wellbeing of young people. Perspectives in Public Health, 130, $86-90$

O'Dea, B. \& Campbell, A. (2011). "Healthy connections: online social networks and their potential for peer support", Studies in health technology and informatics,168, 133-140.

O'Dea, B. \& Campbell, A. (2011) "Online social networking amongst teens: friend or foe?", Studies in health technology and informatics, 167, 133-138. 
O'Neill, B., Livingstone, S. and McLaughlin, S. (2011). Final recommendations for policy, methodology and research. LSE, London: EU Kids Online.

Orchard, L.J. \& Fullwood, C. (2010). Current perspectives on personality and Internet use. Social Science Computer Review, 28(2), 155-169.

Pantic, I., Damjanovic, A., Todorovic, J., Topalovic, D., BojovicJovic, D., Ristic, S. \& Pantic, S. 2012, "Association between online social networking and depression in high school students: Behavioral physiology viewpoint.", Psychiatria Danubina, 24(1) 90-93.

Parris, L., Varjas, K., Meyers, J. \& Cutts, H. 2012, "High school students' perceptions of coping with cyberbullying.", Youth \& Society, 44(2) 284-306.

Pea, R., Nass, C., Meheula, L., Rance, M., Kumar, A., Bamford, H., Nass, M., Simha, A., Stillerman, B., Yang, S. \& Zhou, M. 2012, "Media use, face-to-face communication, media multitasking, and social well-being among 8- to 12-year-old girls.", Developmental psychology, 48(2), 327-336.

Population Division UN-DESA World Population Prospects: 2010 Revision. Accessed Online July 27th 2013. Available at http://www.unfpa.org/webdav/site/global/shared/factsheets/One\%20pager\%20on\%2 0youth\%20demographics\%20GF.pdf

Popay, J., Roberts, H., Sowden, A., Petticrew, M., Arai, L., Rogers, M., \& Britten, N. (2006). Guidance on the conduct of narrative synthesis in systematic reviews. ESRC Methods Program. Retrieved March 21st, 2013 from http://cpd.conted.ox.ac.uk/ healthsciences/courses/short_courses/qsr/NSguidanceV1-JNoyes.pdf

Putnam, R. D. (2000). Bowling Alone. New York: Simon \& Schuster.

Quinn, S. V., \& Oldmeadow, J. A. (2012). Is the iGeneration a 'We' generation?: Social networking use and belonging in 9-13 year olds. British journal of developmental psychology

Rodgers, M., Sowden, A., Petticrew, M., Arai, L., Roberts, H., Britten, N., Popay, J. (2009). Testing methodological guidance on the conduct of narrative synthesis in 
systematic reviews: effectiveness of interventions to promote smoke alarm ownership and function. Evaluation. 15(1): 49-73

Rousseau, D. M. 2011. Reinforcing the micro/macro bridge: Organizational thinking and pluralistic vehicles. Journal of Management, 37: 429-442.

Ryan, R. M., and Deci, E. L. (2001). On happiness and human potentials: A review of research on hedonic and eudaimonic well-being. Annual Review of Psychology, 52, 141-166. DOI: 10.1146/annurev.psych.52.1.141

Ryff, C, D and Keyes, C, L, M. (1995). The structure of psychological well-being revisited. Journal of Personality and Social Psychology. doi: 10.1037/00223514.69.4.719. PMID: 16508343

Ryff, C, D., and Singer B. (1998). The contours of positive human health. Psychological Inquiry, 9, 1-28

Ryff, C, D., and Singer B. (2000). Interpersonal flourishing: a positive health agenda for the new millennium. Personality and Social Psychology Review, 4, 30-44. doi: 10.1207/S15327957PSPR0401_4

Ryan, T. Xenos, S. (2011). Who uses Facebook? (2011). An investigation into the relationship between the Big Five, shyness, narcissism, loneliness, and Facebook usage. Computers in Human Behavior 27, 1658-1664.

Sarriera, J.C., Abs, D., Casas, F. \& Bedin, L.M. (2012) "Relations between media, perceived social support and personal well-being in adolescence.", Social Indicators Research, 106(3) 545-561.

Scott, C, R. (2007). 'Communication and Social Identity Theory: Existing and Potential Connections in Organisational Identification Research', Journal of Communication Studies 58(2), 123-138.

Siporin, M. (1980). Ecological systems theory in social work. Journal of Sociology and Social Welfare, 7(4), $507-532$. 
Siriaraya, P., Tang, C., Ang, S., Pfeil, U., and Zaphiris, P. (2011). A comparison of empathic communication pattern for teenagers and older people in online support communities. Behaviour \& Information Technology. 30(5): 617-628.

Shannon, C, E. and Weaver, W. (1949). A Mathematical Model of Communication. University of Illinois Press.

Stefanone, M.A., Lackaff, D. and Rosen, D. (2011). "Contingencies of self-worth and social-networking-site behavior". Cyberpsychology, Behavior And Social Networking, 14, 41-49. doi: 10.1111/j.1083-6101.2012.01585.x

Stengård, E., and Appelqvist-Schmidlechner, K., (2010) Mental health promotion in young people - an investment for the future. Publications of WHO Regional Office for Europe.

Steinberg L. (2005) Cognitive and affective development in adolescence. Trends in Cognitive Sciences. 9, 69-74.

Sticca, S. Ruggieri, F. Alsaker, S. Perren (2012) Longitudinal Risk Factors for Cyberbullying in Adolescence. Journal of Community \& Applied Social Psychology.

Strasburger V.C., Wilson B.J., Jordan A. (2009) Children, Adolescents, and the Media. 2nd ed. Thousand Oaks, CA, Sage.

Spencer L, Ritchie J, Lewis J, Dillon L (2003). Quality in qualitative evaluation: a framework for assessing research evidence [monograph online]. London: Cabinet Office. Available from: www.gsr.gov.uk/evaluating_policy/era_papers/qual_eval.asp

Taylor, B., Wylie, E., Dempster, M.. and Donnelly, M,. (2007) 'Systematically retrieving research: a case study evaluating seven databases'. Research on Social Work Practice, 17(6), 697-706

Tichon, J. \& Shapiro, M. 2003, "The process of sharing social support in cyberspace", Cyberpsychology \& Behavior, vol. 6, no. 2, pp. 161-170.

Thomas, A. (2006). "MSN was the next big thing after beanie babies": Children's virtual experiences as an interface to their everyday lives. For: E-Learning, 3(2) 126143 
Tomai, M., Rosa, V., Mebane, M. E., D’Acunti, A., Benedetti, M., \& Francescato, D. (2010). Virtual communities in schools as tools to promote social capital with high school students. Computers \& Education, 54, 265-274. doi:10.1016/j.compedu.2009.08.009

Valaitis, R. 2005, "Computers and the Internet: Tools for youth empowerment", Journal of Medical Internet Research. 7(5) 43-52.

Valkenburg, P.M., Peter, J. \& Schouten, A.P. 2006, "Friend Networking Sites and Their Relationship to Adolescents' Well-Being and Social Self-Esteem.", CyberPsychology \& Behavior, vol. 9, no. 5, pp. 584-590.

Vandoninck, S., d'Haenens, L., De Cock, R. \& Donoso, V. 2011, "Social networking sites and contact risks among Flemish youth". Journal of Child Research, 19(1) 6985.

Vandoninck S., d'Haenens L., Roe K. (2013). Online risks: Coping strategies of less resilient children and teenagers across Europe. Journal of Children and Media, 7(1), $60-78$

van den Eijnden, Regina J.; Meerkerk, Gert-Jan; Vermulst, Ad A.; Spijkerman, Renske; Engels, Rutger C. (2008). Online Communication, Compulsive Internet Use, and Psychosocial Well-Being among Adolescents: A longitudinal study. Developmental Psychology, 44(3), 655-665.

von Bertalanffy, L. (1962) "General System Theory - A Critical Review,". General Systems, 7, 1-20.

von Bertalanffy, L. (1972) The history and status of general systems theory. Academy of Management Journal, 15(4), 407-426.

Walther, J, B. (1992). Computer Mediated Communication: Impersonal, Interpersonal and Hyper-personal Communication. Communication Research, 23, 343.

Watts, D, J. (2007). The 'New' Science of Networks. Annual Review Sociology. 30, 243-70. doi: 10.1146/annurev.soc.30.020404.104342 
Williams, A. L., and Merten, M. J. (2013). Romantic relationships among women experiencing obesity: Self-perception and weight as barriers to intimacy. Family and Consumer Sciences Research Journal, 41(3), 284-298.

Wilson, K., Fornasier, S., \& White, K. M. (2010). Psychological predictors of young adults' use of social networking sites. Cyberpsychology, Behavior, and Social Networking, 13(2), 173-177.

Woodstock, L. (2002). 'Public journalism's talking cure', Journalism, 3(1) 37-55. 